Article

\title{
Disintermediation in Social Networks: Conceptualizing Political Actors' Construction of Publics on Twitter
}

\author{
Scott A. Eldridge II ${ }^{1, *}$, Lucía García-Carretero ${ }^{2}$ and Marcel Broersma ${ }^{1}$ \\ ${ }^{1}$ Centre for Media and Journalism Studies, University of Groningen, 9700 AS Groningen, The Netherlands; \\ E-Mails: s.a.eldridge.ii@rug.nl (S.A.E.),m.j.broersma@rug.nl (M.B.) \\ 2 Department of Communication, Universitat Pompeu Fabra, 08018 Barcelona, Spain; E-Mail: lucia.garcia@upf.edu \\ * Corresponding author
}

Submitted: 14 November 2018 | Accepted: 27 February 2019 | Published: 21 March 2019

\begin{abstract}
While often treated as distinct, both politics and journalism share in their histories a need for a public that is not naturally assembled and needs instead to be 'constructed'. In earlier times the role of mediating politics to publics often fell to news media, which were also dependent on constructing a 'public' for their own viability. It is hardly notable to say this has changed in a digital age, and in the way social media have allowed politicians and political movements to speak to their own publics bypassing news voices is a clear example of this. We show how both established politics and emerging political movements now activate and intensify certain publics through their media messages, and how this differs in the UK, Spain and the Netherlands. When considering journalism and social media, emphasis on their prominence can mask more complex shifts they ushered in, including cross-national differences, where they have pushed journalism towards social media to communicate news, and where political actors now use these spaces for their own communicative ends. Building upon this research, this article revisits conceptualizations of the ways political actors construct publics and argues that we see processes of disintermediation taking place in political actors' social networks on Twitter.
\end{abstract}

\section{Keywords}

journalism; networks; politics; public sphere; publics; social media; Twitter

\section{Issue}

This article is part of the issue "Journalism and Social Media: Redistribution of Power?", edited by Marcel Broersma and Scott A. Eldridge II (University of Groningen, The Netherlands).

(C) 2019 by the authors; licensee Cogitatio (Lisbon, Portugal). This article is licensed under a Creative Commons Attribution 4.0 International License (CC BY).

\section{Introduction}

Politicians tweet massively. Of this, we are fairly well assured. Yet whether we follow the news, or scrutinize the bevy of research examining political actors' social media use, we continue to benefit from improving the ways we think about political actors' social media practices, and their hitherto unexplored implications. In this article we therefore shift the gaze slightly to the receiving end, looking not just at how political actors' use Twitter, but for the implications of such use on the recipientstheir publics. Building upon an empirical analysis of the Twitter networks of political actors in the UK, the Nether- lands, and Spain, via Twitter, we explore in this article a conceptual argument for how publics are constructed through the relationships between political actors' Twitter accounts and those within their networks. This places a critical lens on how we understand the interrelation between the public, the press, and political power centers as they continue to evolve in a digital age.

Specifically, this article aims to address discrepancies in our fulsome understanding of the political-public relationship by exploring the implications of the direct communicative practice of political actors on Twitter. We show how this is not only a development in the way political speech manifests in contemporary societies, but also 
a potential wresting away of this role from the previous intermediaries of political affairs and public concernsthe news media (Broersma \& Graham, 2015). This considers how political actors' tweets may be narrowly aimed at their more engaged publics as an evolution in the conceptualization of a 'constructed public', achieved through messages directed towards particular audiences, based on the perceived expectations those publics hold (Conboy \& Eldridge, 2018, p. 172). In studying the networks within which political actors speak to members of the public, we argue the ways in which political actors have seized on the opportunities of Twitter may signal a power shift in who is the primary constructor of publics. We theorize this as the appropriation of socio-functional roles of public construction which were previously associated with a journalistic field; in other words, away from those who used to have full control over these roles. This article is a first step towards approaching such questions in larger studies, including those using network analyses and longitudinal approaches.

As a way to assess the implications for the ways we understand political actors' ability to construct their publics, we bring into dialogue research on the evolving relationship between the press, public, and political actors, to conceptualize the constituted public within the mediated public sphere. We then offer a social network analysis (SNA) of politicians' and parties' Twitter activities in the UK, the Netherlands, and Spain to explore specifically how political actors construct publics through Twitter and if this differs between media systems. From this analysis, we offer insights into how publics are being constructed on Twitter and ask whether, by employing network analysis, we can identify ways in which publics are assembled. Where politicians succeed in such construction, in our findings we point to potential implications for journalism's erstwhile role as conduit between the political and the public within more dynamic and complex media systems. We situate this discussion as a conceptual argument in order to offer directions for future work which would then consider the content within these networks.

While it has become altogether clear that social media offer a set of media spaces and practices which have been adopted by politicians, in light of a concern that politicians' Twitter use reflects not an enhancement of communication but rather the fragmentation of societies and the dissolution of a normative public sphere, the questions explored become critical for situating such dynamics within the function of Western societies (Batorski \& Grzywińska, 2018; Colleoni, Rozza, \& Arvidsson, 2014). Drawing from a body of work which examines how politicians use online opportunities to connect to the wider populace (Gurevitch, Coleman, \& Blumler, 2009), how social media and Twitter in particular offer avenues for members of the public to lobby their political actors (Graham, Broersma, Hazelhoff, \& van't Haar, 2013; Tromble, 2018), and how the press has been stepped over when this occurs (Graham, Jackson, \& Broersma,
2018), this article looks at the construction of the public alongside the conceptualization of a mediated public sphere, evident within these practices.

Empirically, this article looks to Twitter to examine an active space of public construction for politicians and political movements in a random non-election period in 2018. This allows us to analyze the day-to-day practices of politicians and their ongoing effects on the construction of publics, while the majority of research focuses on politician's online behavior during a short-term peak in election times. Through a comparative analysis of the main accounts of both established and movement politics, we offer an initial assessment of how the construction of publics on social media differs cross-nationally and where this may signal a reorientation of power within the increased commonality of political communication on social media. By comparing movement politics and established politics engaged in the construction of publics, we are able to offer a more holistic snapshot of the use of social media for political speech. Drawing from a conceptual approach to public construction, we offer insights into the broader implications of such a development for the relationships between political actors' and publics, including the role of journalism within such a dynamic.

In doing so, findings contribute to the ongoing discussion of the shifts between media and political actors by looking not only at the presence of social media use by political actors, i.e., the adoption of media logics by political actors (Hepp, 2013), but where this may signal the activation and intensification of specific publics and the extent to which this mode of constructing a public may differ from past findings. Using SNA to assess how publics are constituted in social media, their formations can be understood in terms of the history of imagined, constructed, and addressed publics within western democracies. This article now proceeds on two fronts, first revisiting the conceptual bases for understand the relationships between political actors and their publics, and the intermediation between the two, then exploring where SNA offers methodological opportunities for examining this relationship.

\section{The Political-Press-Public Axes}

How are publics then constructed on Twitter, and specifically by political actors in Europe? In this section we highlight where an idealized vision of democratic society, predicated on an exchange of information and political views between social actors, underpins both scholarly awareness of and concerns about how these communicative practices now take place. In doing so, we draw on familiar themes, from the Habermasian public sphere supposing a rational deliberative space of democratic dialogue from a socio-historical lens (1989) and the role of communicative action in that constitution (1981), to the contestation over how publics should be addressed from Lippmann and Dewey questioning the agency of 'the pub- 
lic' in such dialogue (Marres, 2005), to a range of scholarship which takes into its discussion the nature, strength, and effectiveness of considering a public sphere as a guiding understanding of democratic societies (Couldry, Livingstone, \& Markham, 2007).

However, we find the greatest allegiance with public sphere research where it has developed an understanding not of one broad public, but of many publics. Such work has moved our discussions towards considering publics more complexly and as multiple (Fraser, 1990), including alternative publics (Marx Ferree, Gamson, Gerhards, \& Rucht, 2002), counter-publics (Warner, 2002), and where these have been drawn together in theorizing a digital public sphere online (Dahlgren, 2005; Papacharissi, 2004). In considering how (and whether) politics within Europe have become more fragmented, as both recent elections and recent research has suggested (Bennett \& Pfetsch, 2018), this is a relevant point of departure for our discussion, and all the more critical when considering public formation by political actors for any conception of a public sphere.

While a thorough dialogue between scholars of the public sphere would be beyond the scope of this article, we nevertheless need to highlight where a critical examination of the nature of publics in particular can benefit our examination of the nature of constructed publics. As a starting point for understanding the outward-facing communication of political actors, Warner (2002) offers a useful distinction between the public as the broad, assumptive, and undifferentiated populace within a particular territory or space, and specific publics, as smaller subsets of this larger public which exist based on discrete commonalities, formed by and through communication reinforcing such commonalities. As he argues, such "a public is a space of discourse organized by nothing other than discourse itself....It exists by virtue of being addressed" (2002, p. 50). In line with Warner (2002) we conceptualize the idea of specific publics as groups which are constructed within communicative spaces when addressed, adding that these specific publics can be marshalled towards political ends. In other words, such a public is activated when messages salient to it are amplified within a network (Papacharissi, 2014).

For political actors, understanding 'their' specific public has allowed actors to focus on what types of communication best reinforce their position as it regards their specific publics, refining and tailoring political speech based on this assumption in order to 'tactically' appeal to that public (Ross, Fountaine, \& Comrie, 2015). Inversely, for members of the public an assumption about what constitutes their belonging to a specific public allows individuals to imagine themselves within a group of like-minded individuals, who furthermore share some stake in being seen through such an association (Anderson, 1983; cf. Broersma \& Koopmans, 2010 for examples of 'imagined communities' beyond the nation state). For both political actors and members of the public, specific publics are further constructed when this sense of belonging is made salient through the way that public is addressed-on both levels; this includes being addressed by political actors within campaigning and political speech, but also between members of that public within 'everyday' political talk (Graham, Jackson, \& Wright, 2015). Dahlgren (2005, p. 149) speaks of these as "discursive interactional processes", though he sees greater benefit in moving away from narrow specific publics, arguing broader interactions between specific groups are a key aspect of public formation, enriching civic cultures when members of publics find shared points of interaction beyond their own specific concerns. While this may be ideal, and reflects one way of understanding public formation, it is nevertheless not exclusively the case as we also see publics constituted around an even narrower construction, including as issue publics, also constructed through communicative acts (Poor, 2005).

Taken together, these discussions allow us to approach the construction of publics through the ways members of society are spoken of as a group, and spoken to as a group with a vested interest in certain dialogues within society. When we turn to social media in general and Twitter in particular, we can see this formation of the public as one which "comes into being only in relation to texts and their circulation" (Warner, 2002, p. 50). This involves looking not only to the nature of the communicative content-e.g., political speech, mediated on Twitter-but also the communicative network within which that communication takes place as a reflection of that construction, seeing the formation of these networks through the affordances of the platform as a type of communicative act (Marwick \& boyd, 2010, p. 115). This allows us to both understand network formation as a discourse, and therefore a form of public construction whereby publics are 'coming into being', and the breadth or narrowness of that construction. Breadth is apparent when we think of political actors speaking to audiences of citizens as a collective group in order to reinforce their coherence (Bennett, 2012), and narrowness when we think of these same actors speaking to audiences of potential voters in ways which differentiate one public from another (Bruns \& Burgess, 2011). This is reflected in our first research question:

RQ1: How do different political actors, operating in different political contexts, address the publics they intend to construct on Twitter?

Thus, publics are not seen here as inherent or essentialist, but as constructed when social actors make certain assumptions about their public and when these assumptions are reflected in the ways political actors speak, including how they construct their social media networks. This includes assumptions about what is relevant, or not, to a public, and what would be of interest, or not, to a public. This also considers speech both in terms of the contents of political speech and the organization of com- 
municative networks (i.e., social networks) within which messages are conveyed. This returns our attention to the nature of 'being addressed' for understanding the construction publics through political actors' speaking to members of publics, including where that speech takes place-whether indirectly through journalistic media or directly through political actors' own use of media.

\subsection{Shifting Media Power: From Intermediary to Interlocutor}

From seeing the construction of publics in the ways outlined above, we argue that networks of publics and political actors can be considered as engaged in a process of 'relational construction'. In doing so, we argue, paying attention to the ways these are constructed through communication, between actors, measured in the nodes and edges of a network, is a useful avenue for understanding. Conceptually, we see this as drawing our attention to the shifting roles of news media within the mediated dynamics of political communication. In this section, we consider the publicness of political actors' communication within specific political-journalistic-public axes which have traditionally underpinned a theoretical and normative understanding of the public sphere as discursive, engaged in deliberation of important topics for society, and benefiting from the mediation of these deliberations within society. This is broadly described as the mediated public sphere, wherein media act as key intermediaries between those in power and the wider public within societies (Brands \& Voltmer, 2011; Couldry et al., 2007).

Placing media within the construction of publics for politics begins as a socio-historical question, considering an 'imagined' public and the role news media played previously in shaping an understanding of the public. Benedict Anderson's (1983) and Jürgen Habermas' (1989) theses offer resonant starting points, as each offers a compelling account of the mediation of information as a constructive force for societies, and this force is associated with news media in the traditional sense. From Anderson, we see news as the serialization of our shared narratives which reinforce our sense of communitarian belonging (to a nation). From the Habermasian public sphere where a public seeks to engage in deliberative democratic processes, media provide the public with the information necessary to do so. In each version of understanding the nature of constructed communities (as publics), societies benefited from the mediation of public deliberation towards public understanding throughout history. As Nerone writes, this was a role 'the press'-as a collective institution in western democracies-adopted while promoting their idealized role of informing the citizenry of the affairs of the day (Nerone, 2015, p. 143).

Returning to Dahlgren's emphasis on civic culture, he argues that even within a fractured political environment we can look to see the public sphere and its specific publics more broadly than specific audiences being catered to by specific messages. He sees publics forming based on "minimal shared commitments" (2005, p. 158), of which Dahlgren identifies: values, affinity, knowledge, identities, and practices. In sharing, interaction becomes key in constituting a public, arguing that for the formation of publics, interaction rests on two dimensions:

First, it has to do with the citizens' encounters with the media-the communicative processes of making sense, interpreting, and using the output. The second aspect of interaction is that between citizens themselves, which can include anything from two-person conversations to large meetings. (2005, p. 149)

Moving from Dahlgren's conceptualization to exploring how these are taking place, we can highlight two points of critical divergence: the shift in the nature of 'the media' in this dynamic, and the nature of 'interaction' between political actors and citizens. When Dahlgren raises the idea of "citizens' encounters with the media" as interaction, he points at least obliquely to a view of the media as a consolidated profession (Waisbord, 2013), and as a distinct set of social actors committed to sharing factbased information with a public in their interest, harkening back to the development of 'the press' within democracies (Nerone, 2015). As a substantive member of the public sphere, 'the media' (or 'the press') held a vaunted position within the democratic process, indebted to informing citizenries as an intermediary between the public members of a space-most often a nation-and the powerful within that space-most often political actors. With the increased adoption of media logics by political actors in a digital era, scholars increasingly ask where that may be worth reconsidering by first unpacking how this initially took shape.

To begin with, in these visions of the press intermediating between the public and those in power, there are explanatory challenges. For one, the imagined community version of a public Anderson (1983) offers was predicated in part on the ritualized shared consumption of news content, a dynamic that has been surpassed by the repertoires and individualized practices of social media use (Hasebrink, 2017). Furthermore, the public sphere of Habermas emphasizing deliberation and rationality, has likewise been confronted by the way it negated alternative publics (Fraser, 1990). Upon further scrutiny it struggles to reflect the ways in which publics engage differently (and divergently) in discourse which is neither deliberative nor rational (Boyte, 1992, p. 344; Richards, 2018). That there was an institution committed to idealized informative functions like 'the press' in the first place is also vulnerable to critique, not least in the histories of the news media in the countries we explore here where pillarization in the Dutch context (Wijfjes, 2017), informal political allegiances between parties and news media in the UK (Curran \& Seaton, 2009), and a recent history with authoritarian control in Spain (Siebert, Peterson, \& Schramm, 1956), each offers specific counternarratives to such a vision. 
Within these dynamics, we also see where news media have been shown to be far from neutral arbiters of information for an idealized public good, as they are also invested in constituting specific publics which they imagine, speak to, and strive to maintain-particularly from the early twentieth century onward, as an increasingly literate populace and an increasingly industrial press saw the need to understand, address, and grow a public (Steel \& Broersma, 2016). As Conboy and Eldridge (2018) have argued, news media while often wedded to democratic inclinations nevertheless benefit from imagining publics they can assume, address, and in ideal circumstances rely on for economic support through ongoing readership. News publics historically, however, were rarely truly known; in line with Anderson (1983), they were at best 'imagined' as consolidated groups of social actors (sometimes imagined with the benefit of market research which gave some measure of their interests).

Once we accept that publics are imagined, and we begin to consider how they are addressed as such through what the newspapers identified as important for that public, we can see as well where members of the public could hold at least some expectation that the press would speak up on their behalf. While in reality this picture has also struggled in its idealism (Hampton, 2010), we nevertheless see in it how publics are constructed within the discursive spaces where they are addressed. As news media 'interacted' with their specific publics, employing language which activated the communities they spoke to and making salient the topics which they saw as importance (cf. Conboy, 2006 for an illustrative discussion of this dynamic with British tabloids), in a parallel construction to the ways political actors imagine, speak to, and make salient issues relevant to a public, thereby constructing that specific public.

As above, whether disaggregating a public into publics, or critiquing the ability of the press to genuinely speak for the public and not just against the powerful (Steel, 2017), cracks in the normative picture of journalism as serving democratic ends through constructing this public have been made evident (Eldridge \& Steel, 2016). This is where we find ourselves in this article, emerging from the first two decades of the twenty-first century with new questions to be explored about the relationship between publics, the press, and political actors who, as the arguments from theory allow, warrant reimagining within ever-evolving communicative relationships. This brings us to a point of seeing the construction of a public not only as a political exercise, outlined above, but as an exercise endeavored by media interested in securing audiences. This points to our second research question:

RQ2: Do political actors' Twitter networks reflect a power shift in terms of the construction of a public?

Taking this as an entree towards reflecting the relationships constructed within democratic spaces, the conception of a constructed public offers us a path towards ex- amining how communication between groups of social actors can lead to the mediated construction not of the public, but of certain publics. In line with Griffin (1996), and Fraser (1990), this takes a view within democratic societies of publics as multiple-coexisting in differentiated public spheres within societies-where multiple constructions may emerge.

\subsection{Towards Reimagining the Constructed Public: Shifting Power}

Some of the questions posed above have initial hypotheses which we can consider, pointing us toward scholarship on the mediatization of politics as a broad set of literature which explores one aspect of this reimagining (cf. Hepp, Hjarvard, \& Lundby, 2015, as a starting point). From work on mediatization, we no longer look to the press as the intermediary between political actors and the publics they speak to, and now recognize political actors doing this on their own accord, and as the discursive spaces of political activities as more hybrid (Chadwick, 2017). To the extent mediatization speaks to the ways in which political actors in particular have embraced media logics to achieve political ends, we see this initially as mapping political communication onto the expectations of a political journalistic class (Strömbäck, 2008, p. 236). However, as social media took hold, politicians could step past journalists altogether and directly address their public audience (Broersma \& Graham, 2015). In recent years, this ability of political actors to reach beyond news media has not only left journalistic actors outside the mediation of politics, it has also resulted in journalists acting more as interlocutor than intermediary. They are resigned at times to an outsider position, reacting to rather than establishing the salient discussions of politics (Eldridge \& Bødker, 2018).

Where the concept of mediatization speaks at length to the shifting of media and political logics between media and political actors, as Broersma and Graham (2015) write, with social media this is not merely an adaptation of media forms for campaign or political speech. Such shifts also reflect a push to consolidate power within the communicative spaces of online media, overtaking others who previously held such control. Broersma and Graham describe processes of adaptation, as politicians adopting Twitter as a means of communicating directly with publics, thereby mollifying the initial challenge posed by social media which emerged as alternative communicative venues, outside their and journalism's traditional routines. Lest journalists cry foul at such developments, their own adoption of Twitter also moved towards muting the challenge social media posed to their own practices (Lasorsa, Lewis, \& Holton, 2012; Parmelee, 2013). This does, however, highlight where aspects of mediatization as the adoption of media logic by political actors, may have now developed further towards disintermediation-or the specific absenting of journalistic actors from their traditional role as communicators 
between publics and politics (Katz, 1988; Katz \& Dayan, 1994). To the extent this emerges within networks of political and public actors, the implications for journalism within democratic societies warrant renewed consideration within the context of our third research question.

RQ3: What are the broader implications of this power shift for the socio-functional roles of journalistic actors?

\section{A Network Approach to Public Construction}

The approach of using social networks as an analytical frame focuses on the different kinds of relationships between actors which form the social system, including between political actors and their publics (Borgatti, Everet, \& Johnson, 2013). Social networks are operationalized as empirical phenomena of social relations in a concrete social or cultural context which have their own characteristics (Belloti, 2015; Borgatti et al., 2013). Critical for this understanding is seeing online networks as one manifestation of social networks, recognizing such networks provide structure to society and exist beyond the digital spaces where they are perhaps most visible.

Focusing first on the online space and digital networks, key authors who have developed SNA point out the relevance of the social networks in the discussions or conversations taking place among different actors. Through analysis, we can see where these conversations are bidirectional and where they are multidirectional (Aragón, Gómez, García, \& Kaltenbrunner, 2017), and how the social space is formed by different actors (as nodes) and the communication exchange between them-so-called links or edges (Borgatti et al., 2013). These actors - in our study, political parties and politicians-have their own characteristics; so-called attributes, through which it is possible to categorize, define, and differentiate each node (Borgatti et al., 2013).

When looking at the relationship between nodes, we are focused on 'relational events' (Atkin, 1977). Relational events are not a permanent relationship established between actors, rather they are relationships established for particular ends or during particular moments-in our case non-campaigns, as off-peak political moments. This kind of digital network relationship is formed by interactions and flows, where flows are outcomes of the different interactions and the interactions are part of the medium or context of these nodes (Borgatti et al., 2013).

There are two kinds of SNA. First is the analysis of the whole network; second is the analysis of the nodes, or actors, which form the network. For the whole network analysis, we use cohesion indicators (including density, reciprocity, and transitivity). For the nodes analysis, we use degree centrality (including in-degree and outdegree), as well as measures of between, eigenvector, and closeness centrality. According to Freeman (1979) in his research on offline social networks, the degree value is understood as the number of connections between nodes or vertices and it is possible to differentiate between the connections that a node receives (indegree) and the connections that a node sends (outdegree). This concept is especially relevant because it allows researchers to identify the role each node plays within a network, including social media networks.

In this approach, there are two kind of nodes which can be categorized according to the value of in-degree and out-degree centrality. On the one hand there are programmers, which have a high in-degree value. These are the nodes that set the message and define the framework of the conversation within a network of actors. Second in such a network are mobilizer nodes. These have a high out-degree value, and are primarily involved in disseminating the message within the social network (Padovani \& Pavan, 2016).

\subsection{The Cases}

This article examines the tweets of political actors (parties and politicians) in the UK, the Netherlands, and Spain and the ways they use Twitter. Using SNA approaches, we examine within the network activities of such actors the ways in which publics are being constructed; a finding of this would reinforce the supposition that political actors have further shifted power from journalistic actors. As an approach towards identifying where specific publics may or may not be addressed, it further takes into consideration the nature of that construction, how dynamic the resultant publics are, and whether the perception of fragmented publics has been realized or, alternatively, where it may be overstated.

By selecting three countries with different media systems-Liberal (UK), Democratic Corporatist (the Netherlands), and Polarized Pluralist (Spain)-we can see where different patterns of public construction relate to the historical nature of these countries media systems, and the closer or further connection between media and political actors in each (Hallin \& Mancini, 2004). This addresses a (largely) two-party political system and liberal, very competitive media system in the UK, a corporatist system in the Netherlands where many parties compete in such a way where ruling coalitions are the norm, and a media system which has (historically) reflected this and has a strong public ethos, and the polarized pluralist Spain, where media and politics both reflect a dynamic, multi-party, system. Using these examples and this approach, this article offers a study of the supposed emergence of narrow political publics, being catered to by specific political actors to the exclusion of others.

We analyze the Twitter accounts of seat-holding parties in parliament and their leaders. All accounts were gathered through Twitter's REST API, using the software package COSMO, developed by the University of Groningen. Unfortunately, not all accounts returned data in the given period. However, this approach provided us with enough material to further theoretically explore how 
publics are constructed on social media, the aim of our article. We chose the period of 9 June till 7 July 2018 to avoid any specific political campaign or election period in any of the three countries. In such cases more heightened activity and more specific types of constructionthe construction of an electorate, rather than a public, geared towards voting, promoting a platform, etc.would be anticipated. For each of the countries we have studied, this timespan also follows periods of particular political tumult, from the June 2017 General Election in the UK under the cloud of carrying out Brexit, to the March 2017 General Election in the Netherlands, which was followed by more than 200 days of negotiations to form a governing coalition, to the Spanish General Election in June 2016, and more pointedly the Catalan independence referendum in October of 2017. By choosing a period of relatively low formal political activity, we hope to gain a fuller picture of the construction of publics outside of the more persuasive activities of such periods (i.e., to see the construction of publics, rather than merely the appeal for potential votes). The total number of tweets per country are highlighted below (Table 1 ). Thus, it is possible to identify the number of tweets ( $\mathrm{N}$ tweets), and accounts media, journalists, and citizens ( $\mathrm{N}$ actors analyzed) with whom politicians and political parties interact (the edges column).

\subsection{Nodes Analysis: Findings}

From this point, by examining the so-called ego networks of these accounts (Borgatti et al., 2013; Pérez-Altable, 2015), we work in line with Elisa Bellotti's thesis that "network science starts from the observation of actors entangled in meaningful relations in contextualized environments" (2015, p. 3). SNA allows us to focus on the official Twitter accounts of the 18 political parties and the 22 accounts of politicians as nodes, allowing us to better know how centralized the political networks and engagement of these actors through the ways they act, interact, and connect with other nodes (Table 2). We generated the three node lists from our dataset using UCINET software, indicating the name of the node (the political party or politician's Twitter handle) that is 'sending' a tie (a tweet or message) and how many ('N tweets') are sent (Borgatti et al., 2013).

\subsection{Whole Network Analysis: Findings}

The whole network analysis is based on cohesion measures; in other words, the connections between the nodes (actors) that form networks. Cohesion is understood as the structure of the network according to the relation in terms of proximity or distance between the

Table 1. Total number of tweets analyzed, per country.

\begin{tabular}{lccr}
\hline Country & N tweets & N actors analyzed & Edges \\
\hline Spain & 7746 & 1534 & 9307 \\
The Netherlands & 975 & 408 & 789 \\
United Kingdom & 5135 & 1694 & 5637 \\
\hline
\end{tabular}

Table 2. Accounts analyzed, per country.

\begin{tabular}{|c|c|c|c|c|c|}
\hline $\begin{array}{l}\text { Spanish Twitter } \\
\text { accounts }\end{array}$ & $\mathrm{N}$ tweets & $\begin{array}{l}\text { Dutch Twitter } \\
\text { accounts }\end{array}$ & $\mathrm{N}$ tweets & $\begin{array}{l}\text { United Kingdom Twitter } \\
\text { accounts }\end{array}$ & $\mathbf{N}$ tweets \\
\hline @marianorajoy & 16 & $@ v v d$ & 23 & @10downingstreet & 91 \\
\hline @Rafa_Hernando & 229 & @dijkhoff & 12 & @theresa_may & 58 \\
\hline @PSOE & 750 & @groenlinks & 78 & @UKLabour & 223 \\
\hline @sanchezcastejon & 76 & @jesseklaver & 14 & @jeremycorbyn & 258 \\
\hline @ahorapodemos & 816 & @MarijnissenL & 47 & $@$ theSNP & 834 \\
\hline @Pablo_Iglesias_ & 360 & $@ p v d a$ & 92 & $@$ NicolaSturgeon & 295 \\
\hline @CiudadanosCs & 1898 & @LodewijkA & 138 & @LibDems & 269 \\
\hline @Albert_Rivera & 303 & @christenunie & 64 & @vincecable & 80 \\
\hline @Esquerra_ERC & 1927 & @50pluspartij & 97 & @duponline & 129 \\
\hline @JoanTarda & 153 & $@$ HenkKrol & 89 & @DUPleader & 52 \\
\hline @ehbildu & 818 & $@$ @eesvdstaaij & 52 & @sinnfeinireland & 918 \\
\hline \multirow[t]{5}{*}{ @oskarmatute } & 400 & @F_azarkan & 105 & @MaryLouMcDonald & 225 \\
\hline & & @fvidemocratie & 164 & @Plaid_Cymru & 1030 \\
\hline & & & & @thegreenparty & 234 \\
\hline & & & & @CarolineLucas & 263 \\
\hline & & & & @jon_bartley & 176 \\
\hline Total & 7746 & Total & 975 & Total & 5135 \\
\hline
\end{tabular}


actors, and the structure of the network according to the connections or exchanges between nodes. If the network of a political party is not cohesive, this would show little to no relationship between party members. In considering the sociality of networks, this would indicate a negative structure to the party when it comes to decisionmaking. Table 3 reveals the density and transitivity values which contribute to the overall cohesion of the three whole networks analyzed. Density is understood as the relationships within a network regarding the potential number of connections. According to the density value, a high density means a trusted network with an important communication exchange (where 0 is no cohesion and 1 is completely cohesive). Thus, big networks formed by a large number of nodes often have a low density, and inversely smaller networks are often denser and more cohesive (Coleman, 1988, as cited in Kane, Alavi, Labianca, \& Borgatti, 2014).

Transitivity, on the other hand, measures the probability that two nodes have a relationship if both have a third node in common. The more nodes that are related, the more likely it is that third node will also be related to the first ones, resulting in a homogeneous network (e.g. my friends' friends are my friends; Kane et al., 2014). As Table 3 shows, the cohesion of each of the three networks is not significant, which reflects perhaps the nature of discord between political actors or the diversity of leaders and accounts examined, and may further reflect the breadth of these networks.

From the second level of analysis-the characteristics of the nodes within each network, the degree centrality (in-degree and out-degree)-we can differentiate between programmers (Table 4) and mobilizers (Table 5). This distinguishes between actors which are able to set the message more than any other accounts (programmers), and those which mostly respond to these 'programmer' messages through the affordances of Twitter, including retweets, likes, or quoting, as 'mobilizers'. Eigenvalue centrality ranges from zero to infinity. Therefore, the higher the value, the greater the indegree or the out-degree. Looking at the degree centrality of each type of actor, we can see the extent to which different actors are effectively using communicative acts in ways which help to establish publics, either through being prominent or establishing their voices as prominent, and second where they are effective at being further amplified by their followers and those who interact with them.

\subsubsection{Spain}

In the Spanish case, Figure 1 shows @sanchezcastrejon, @PSOE, @CiudadanosCs and @ahorapodemos in green; @Esquerra_ERC, in orange; and @Alber_Rivera, in blue. The different colors reflect different kinds of nodes according to the modularity of the network, where modularity is understood as the diverse groups of nodes. This figure reflects how groups of nodes (those with the same color) have strong connections on Twitter between themselves. The size of the labels is based on the in-degree centrality; in other words, which actor sends the message in the Spanish network we explore.

Table 3. Network cohesion, by country.

\begin{tabular}{lrrrrrr}
\hline Network & \multicolumn{2}{c}{ Spain } & \multicolumn{2}{c}{ United Kingdom } & \multicolumn{2}{c}{ The Netherlands } \\
\hline Density & $0.1 \%$ & 0.001 & $0.3 \%$ & 0.003 & $6.7 \%$ & 0.067 \\
Transitivity & $11.6 \%$ & 0.116 & $0.9 \%$ & 0.009 & $7.9 \%$ & 0.079 \\
\hline
\end{tabular}

Table 4. Programmers, by country.

\begin{tabular}{|c|c|c|c|c|c|}
\hline \multicolumn{2}{|c|}{ Spain Programmers } & \multicolumn{2}{|c|}{ United Kingdom Programmers } & \multicolumn{2}{|c|}{ The Netherlands Programmers } \\
\hline @marianorajoy & 1000 & @10downingstreet & 0 & $@ v v d$ & 2000 \\
\hline @Rafa_Hernando & 0 & @theresa_may & 7000 & @dijkhoff & 1000 \\
\hline @PSOE & 6000 & @UKLabour & 4000 & @groenlinks & 1000 \\
\hline @sanchezcastejon & 7000 & @jeremycorbyn & 4000 & @jesseklaver & 3000 \\
\hline @ahorapodemos & 3000 & @theSNP & 4000 & @MarijnissenL & 1000 \\
\hline @Pablo_Iglesias_ & 2000 & @NicolaSturgeon & 1000 & $@ p v d a$ & 0 \\
\hline @CiudadanosCs & 3000 & @LibDems & 2000 & @LodewijkA & 2000 \\
\hline @Albert_Rivera & 3000 & @vincecable & 2000 & @christenunie & 1000 \\
\hline @Esquerra_ERC & 4000 & @duponline & 2000 & @50pluspartij & 1000 \\
\hline @JoanTarda & 1000 & @DUPleader & 1000 & @HenkKrol & 1000 \\
\hline @ehbildu & 1000 & @sinnfeinireland & 1000 & @keesvdstaaij & 2000 \\
\hline \multirow[t]{5}{*}{ @oskarmatute } & 1000 & @MaryLouMcDonald & 1000 & @F_azarkan & 0 \\
\hline & & @Plaid_Cymru & 1000 & @fvidemocratie & 1000 \\
\hline & & @thegreenparty & 1000 & & \\
\hline & & @CarolineLucas & 4000 & & \\
\hline & & @jon_bartley & 2000 & & \\
\hline
\end{tabular}


Table 5. Mobilizers, by country.

\begin{tabular}{|c|c|c|c|c|c|}
\hline \multicolumn{2}{|c|}{ Spain Mobilizers } & \multicolumn{2}{|c|}{ United Kingdom Mobilizers } & \multicolumn{2}{|c|}{ The Netherlands Mobilizers } \\
\hline @marianorajoy & 6000 & @10downingstreet & 24000 & @vvd & 5000 \\
\hline @Rafa_Hernando & 46000 & @theresa_may & 18000 & @dijkhoff & 10000 \\
\hline @PSOE & 226000 & @UKLabour & 99000 & @groenlinks & 33000 \\
\hline @sanchezcastejon & 29000 & @jeremycorbyn & 102000 & @jesseklaver & 1000 \\
\hline @ahorapodemos & 189000 & @theSNP & 343000 & @MarijnissenL & 23000 \\
\hline @Pablo_Iglesias_ & 162000 & @NicolaSturgeon & 244000 & @pvda & 38000 \\
\hline @CiudadanosCs & 257000 & @LibDems & 68000 & @LodewijkA & 87000 \\
\hline @Albert_Rivera & 115000 & @vincecable & 45000 & @christenunie & 43000 \\
\hline @Esquerra_ERC & 428000 & @duponline & 69000 & @50pluspartij & 37000 \\
\hline @JoanTardā & 103000 & @DUPleader & 29000 & @HenkKrol & 29000 \\
\hline @ehbildu & 198000 & @sinnfeinireland & 214000 & @keesvdstaaij & 31000 \\
\hline \multirow[t]{5}{*}{ @oskarmatute } & 184000 & @MaryLouMcDonald & 158000 & @F_azarkan & 68000 \\
\hline & & @Plaid_Cymru & 269000 & @fvidemocratie & 61000 \\
\hline & & @thegreenparty & 85000 & & \\
\hline & & @CarolineLucas & 125000 & & \\
\hline & & @jon_bartley & 71000 & & \\
\hline
\end{tabular}

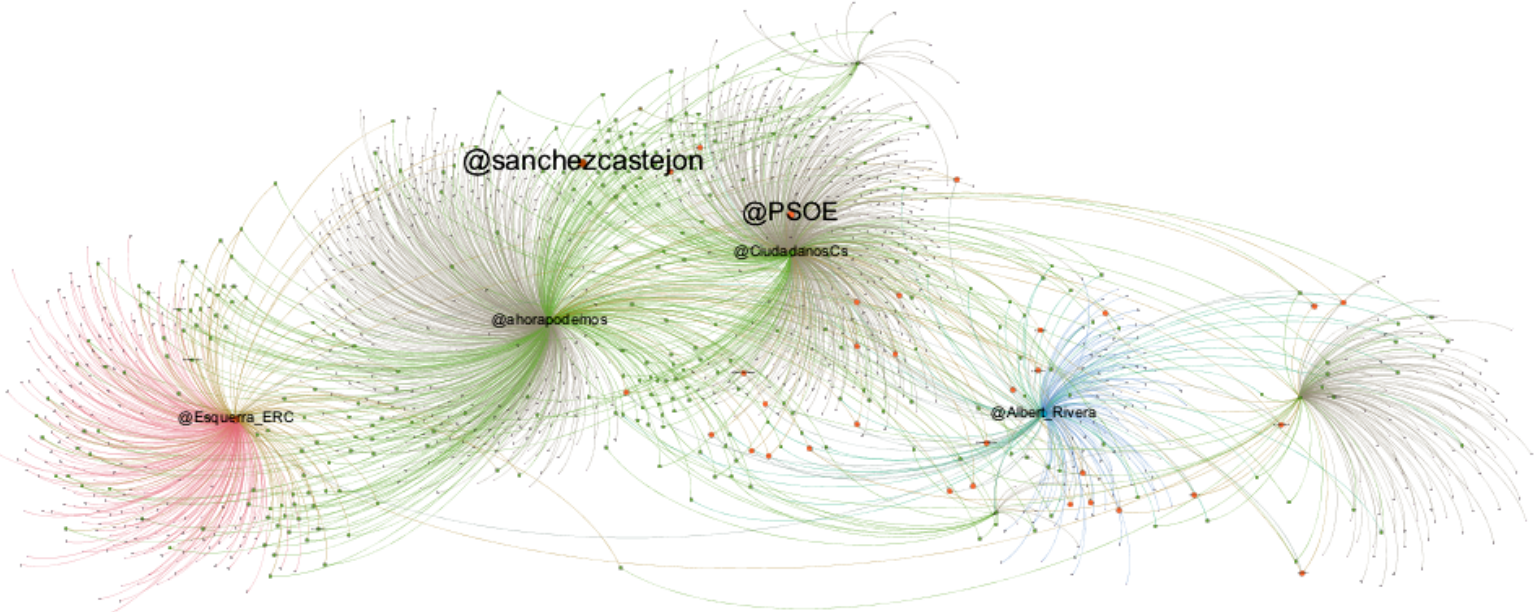

Figure 1. Twitter network, Spanish case.

In such a network, we can see that the @PSOE account (Spanish Socialist Workers' Party, the traditional center-left wing party) and its candidate @sanchezcastrejon are the primary programmers within the network, able to disseminate political messages effectively. Then, we find @Esquerra_ECR (Esquerra Republicana de Catalunya), @ahorapodemos (a new left party), @CiudadanosCs (centre-right party) and @Albert_Rivera (Ciudadanos' party leader). In contrast, we find that @Rafa_Hernando (Partido Popular political leader) is not a programmer, but rather he spreads the message in the Spanish network-a mobilizer role. The density (0.01) and transitivity (0.116) values suggest that the Spanish network is not cohesive-which is common in big networks-though this also reflects this is a hierarchical network. As regards media, we also see that media Twitter accounts are mentioned by the political parties and politicians, including @rtve, @europapress, @elprogramaAR, @telecinco or @tve_tve. However, the main purposes of these mentions are related to appearances of the politicians in the media and, in these cases, the message remains set by parties and politicians and not media.

\subsubsection{United Kingdom}

Within the UK results, the account that stands out above all is that of Conservative party leader and Prime Minister Theresa May. The in-degree value for her account is notably higher than the others, followed by the parties' accounts @uklabour (UK Labour party) and @theSNP (Scottish National Party) and by the politicians @jeremycorbyn (Labour Party Leader) and @CarolineLucas (former Green Party leader). Figure 2 shows the actors which set the message-programmers-with purple nodes and larger labels. In this case, we want to highlight the role played by @Plaid_cymru (Party of Wales) and @sinnfeinireland (Sinn Fein; the Irish Republican party) ac- 


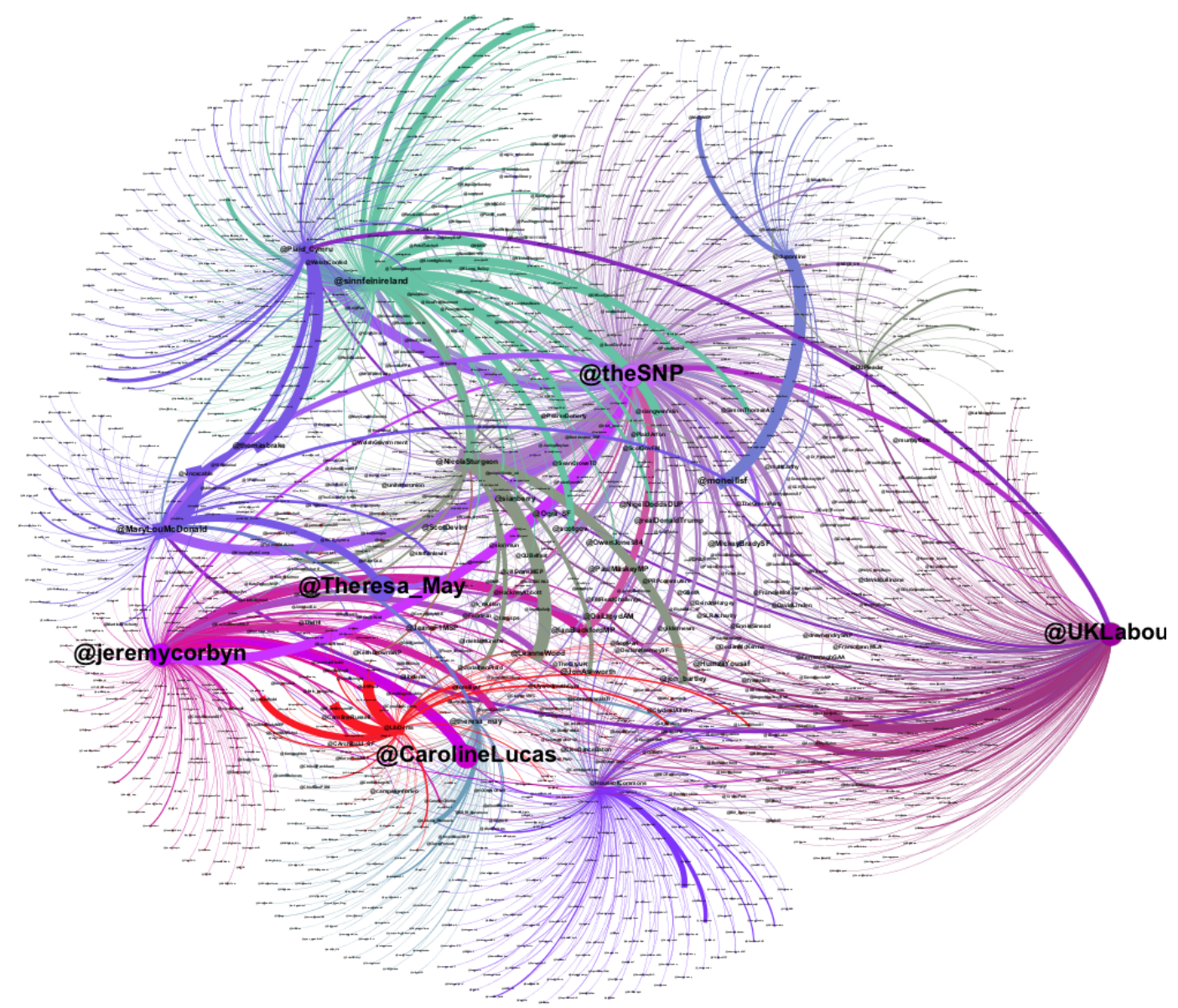

Figure 2. Twitter network, UK case.

counts. During the period of analysis, these Twitter accounts were active in spreading the message which programmers set, acting as mobilizers. In addition, while media and journalism accounts were found, such as @thetimes or the festival account @TWT_Now, the degree values are not significant, reflecting little interaction with these accounts. Based on cohesion values, similar to the Spanish case, the British network is also not cohesive and is also a hierarchical network, based on the density (0.003) and transitivity (0.009) values.

\subsubsection{The Netherlands}

Finally, our analysis of the Dutch case is based on the smallest network, which (as shown in in Figure 3) allows us to address clearly which political actors set the message as programmers (big labels, red nodes) and which nodes spread the message as mobilizers. In this sense, we are able to gain clearer insights into how publics are being constructed and the nature of these publics. In Figure 3, there is an equilibrium or kind of competition to set the message. The account of Groen Links leader Jesse Klaver has the highest value and overall, this account and those of the @vvd (Conservative party), @LodewijkA (PvdA leader) and @keesvdstaaij (SPG leader), are the primary programmers; with the exception of the VVD, we there- fore see the message within the network being set by politicians' accounts instead of by political party accounts.

Despite the fact that the Dutch network is smaller than those previously analyzed-which could be supposed to be more cohesive, and less hierarchical-the results of density (0.067) and transitivity (0.079) discard this thesis.

\section{Discussion: An Initial Prognosis for Considering Publics}

In closing, we want to point to what the SNA approach offers us in terms of insights into the construction of publics within these three discrete national contexts, and what the activities on Twitter of political actors and parties in each case indicate for our understanding of publics in Western democracies. When considered against the theoretical understanding of public construction we posed at the outset, we will unpack our data as a reflection of that dynamic. However, we want to first highlight a specific challenge in understanding 'publics' in these contexts encountered within social media research. We tactically chose a discrete sample of seatholding prominent news actors, which limits the scope of our empirical analysis. As we looked at a non-campaign period, these are, first, the most active voices once elec- 


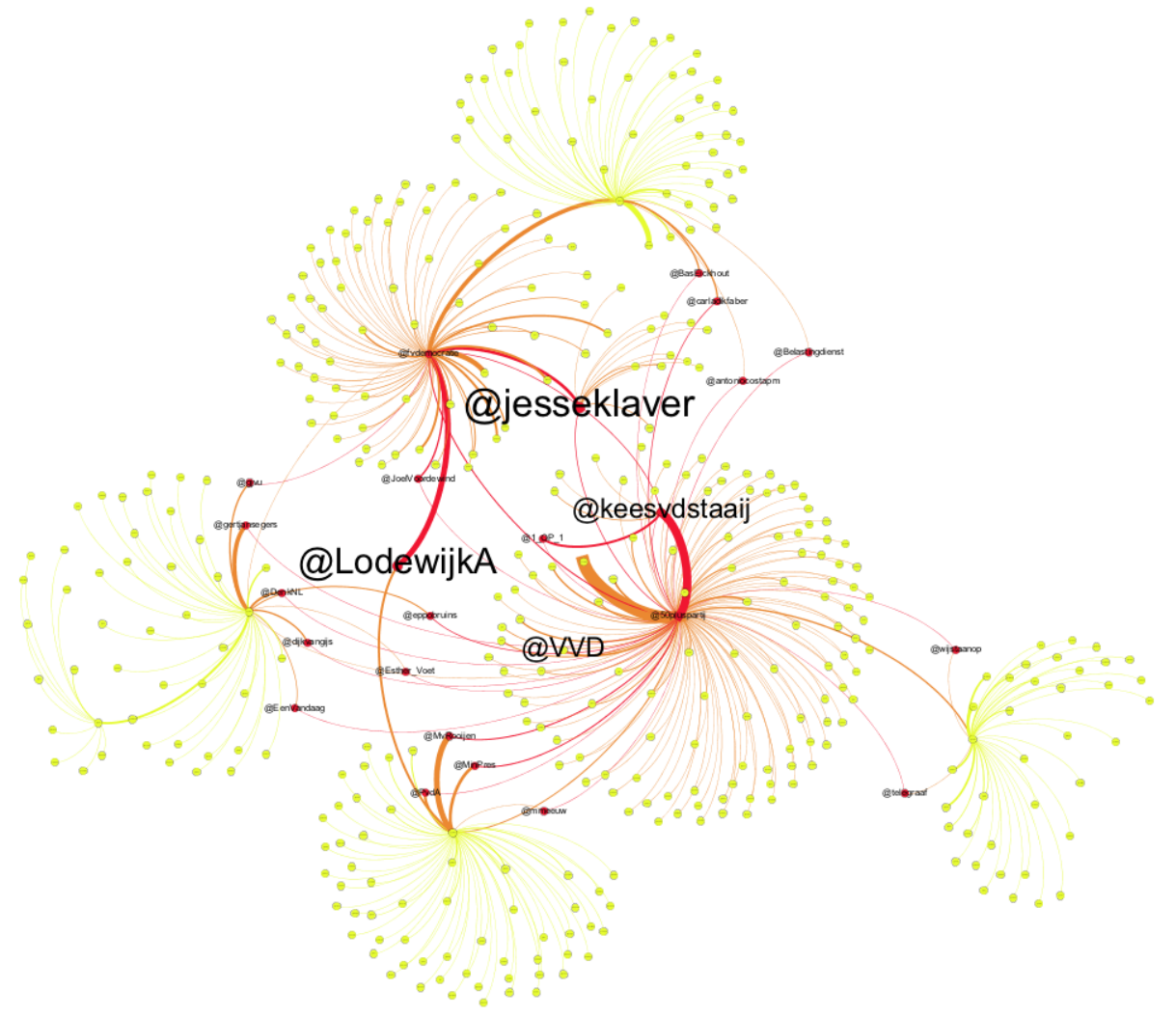

Figure 3. Twitter network, Dutch case.

tions have closed, and their followers are more likely to be highly engaged. It would also be interesting for further research to trace the construction of publics over time to understand how publics might be continuously reassembled. Second, it would be difficult if not impossible to capture the diversity of accounts which may also be engaging in political speech beyond established parties and actors, such as journalists and news organizations, through alternative approaches within the scope of this article.

Nevertheless, we can draw on empirical and methodological insights from our SNA approach to return to the conceptual debates we outlined above. These offer us a view into how publics are being constructed on Twitter outside election periods. First, we do not see a bidirectional or multidirectional communicative media. Instead, within whole networks and the analysis of political actors we overwhelmingly see the absence of cohesion, this is the case in both large and smaller networks. In other words, we are able to observe that while it is possible to differentiate among groups of nodes corresponding to the different parties and their candidates, we do not see indications of an active exchange or conversation among them. Secondly, through the nodes analysis we are able to conclude that in the case of the UK and Spain there are fewer nodes which set the message-fewer programmers - than there are nodes which spread the message. By contrast, in the Netherlands, the message is set and spread by a higher number of political actors and this takes place in in a more balanced way. Here we find that from the networks we analyzed we are able to rethink how public construction is taking place and the familiar tripartite framework of news media, public, and political actors, with an awareness of the limitations of such an approach and within our specific study (for instance, it focuses on one social media, which is just one locus of public construction). This addresses our first research question.

We also see reflected in our analysis some extant understanding of political parties' and actors' construction of publics from this analysis - in that it is actively engaged in doing so-and we can see where this is varied across national contexts. Within the British network, for instance, we are unsurprised when we see the Prime Minister, Theresa May, as both a political agenda setter and a prominent public figure within the mediated discourse of politics. It is unsurprising her Twitter account is also prominent within this network. However, despite there being a number of seat-holding parties in the UK, within the structure of the network we do not see other parties which have pronounced specific target publics (e.g., Plaid Cymru and Wales) also reflecting programmer roles. Instead, we see they are more inclined to interact with tweets from May. This may reflect the overwhelming prominence of Britain's top two parties, contra the Dutch case where coalition governments are the norm and where we see more actors in programmer roles. Similarly, in the Spanish case the network analysis shows the highly fragmented nature of politics 
at a time when elections and referenda have widened, rather than smoothed over, political differences (Esteve del Valle \& Borge Bravo, 2018). While in the Spanish and UK networks this might suggest some tendency towards the Habermasian ideal of a unified public sphere (one in which everyone can take note of issues and these are addressed and discussed with the public at large) we are wary to conclude such a space, as this fails to account for the elite dominance we also witness in terms of network hierarchies. In the Netherlands, however, we certainly seem to observe more of a fragmentation of the public sphere, something past findings and research would allow us to anticipate. This finding responds to our second research question.

We would like to now turn to our final research question-What are the broader implications of this power shift for the socio-functional roles of journalistic actors?-to advocate, in closing, for a renewed agenda for exploring the orientation of power between news media, political actors, and publics. What we argue here is that beyond politicians eliding gatekeepers as they actively construct publics online (Broersma \& Graham, 2015), or journalists soliciting from Twitter public and political commentary (Harder \& Paulussen, 2016), we see an elision of journalistic roles in the construction of publics by politicians on Twitter. The work here shows a circumventing of the previous politician/public orientation which was predicated on a role for news media (Strömbäck \& Esser, 2017), and rather we see in the Twitter activity from and by political actors the specific constitution of their publics.

Thus, we look from these discussions to ask where the dynamics have shifted from a Habermasian intermediary towards a discourse possibly between politicians and the public, where news media are otherwise exempted. As Strömbäck and Esser (2017) and Van Aelst and Walgrave (2017) reflect in conversation with each other, we may be able to transport the 'information' and 'arena' functions of media onto networks of Twitter-in particular considering how politicians use media as a resource for public appeal, and for political message transmission. This is mirrored in the assessment of 'programmers' and 'mobilizers'. Such findings give us some latitude to suppose that the mediated politics occurring on Twitter is not only according to an informative function (to disseminate political messages, or garner feedback) but also to consider where the platforms now acts as a discrete media arena of politics; in other words, where the network reflects not merely discourse acts which construct publics (Warner, 2002), but as constituting the space within which public construction occurs, including who is involved in that construction.

From these discussions, we note that within Western democracies there is a prevalent set of expectations of political actors to speak (in some fashion) to publics (of some fashion) in order to convey their messages-be it through a dominant press, or through other mechanisms. From this, in lively political climates online, with vari- ous stakeholders committed to various political agendas, the salience of Fraser's (1990) critique that there is no one public and rather many publics has only intensified. Within a mediated public sphere, we can expect to see this reflected also in communicative networks on Twitter. Thus, while we have had some cause to expect more media savvy political activity as the field of politics has increasingly embraced a media logic, the minimal presence of an active engagement with news media within these networks suggest this has moved towards a wholesale adoption of the opportunities of social media for political actors to get their messages out, independent of any intermediating journalistic class on the platform.

The larger questions this raises are intensified by the apparent disintermediation that has emerged in recent years as political actors have availed themselves of the affordances of social media to 'mediatize' their political communication. We see this in our own analysis as well, as news media actors are nearly absent from the networks of political actors, and when they appear they are used instrumentally for promotion. In response to such trends, we ask 'whither journalism?', particularly as we consider journalism's historic role in constructing publics among nations and their near-absence within the networks of major political actors and parties. Consequently, while it seems a rather 'normal' practice nowadays for political actors to approach their publics directly through these social means, this nevertheless opens new questions for the axes that connect political actors, the publics they address, and the role of critical voices in any such engagement.

This article centered its arguments around the direct communication by politicians with their perceived publics as an alternative avenue for understanding the role-or absence of a role-for journalism in these contexts, and in doing so it primarily offers a conceptual discussion of the shifting power center in the political-presspublic triangle. As a field in Western societies which developed in part on speaking to, and in part on speaking for a public, any eliding of the journalistic voice in the construction of political publics has implications for how we speak of the press, politics, and publics within our societies, as each continues to find its footing in a digital age. From the discussions we have outlined here, we argue for a renewed research agenda to continue assessing these dynamics.

\section{Conflict of Interests}

The authors declare no conflict of interests.

\section{References}

Anderson, B. (1983). Imagined communities. London: Verso.

Aragón, P., Gómez, V., García, D., \& Kaltenbrunner, A. (2017). Generative models of online discussion threads: State of the art and research challenges. 
Journal of Internet Services and Applications, 8(15), 1-17. https://doi.org/10.1186/s13174-017-0066-z

Atkin, R. H. (1977). Combinational connectives in social systems. Basel: Birkhanser.

Batorski, D., \& Grzywińska, I. (2018). Three dimensions of the public sphere on Facebook. Information, Communication \& Society, 21(3), 356-374.

Bellotti, E. (2015). Qualitative networks. mixed methods in sociological research. New York, NY: Routledge.

Bennett, W. L. (2012). The personalization of politics: Political identity, social media, and changing patterns of participation. The ANNALS of the American Academy of Political and Social Science, 644(1), 20-39.

Bennett, W. L., \& Pfestsch, B. (2018). Rethinking political communication in a time of disrupted public spheres. Journal of Communication, 68(2), 243-253.

Borgatti, S. P., Everet, M. G., \& Johnson, J. C. (2013). Analyzing social networks. London: Sage Publications Ltd.

Boyte, H. C. (1992). The pragmatic ends of popular politics. In C. Calhoun (Ed.), Habermas and the public sphere (pp. 340-357). Cambridge, MA: MIT Press.

Brants, K., \& Voltmer, K. (2011). Introduction: Mediatization and de-centralization of political communication. In K. Brants and K. Voltmer (Eds.), Political communication in postmodern democracy: Challenging the primacy of politics (pp. 1-16). New York, NY: Palgrave Macmillan.

Broersma, M., \& Graham, T. (2015). Tipping the balance of power: Social media and the transformation of political journalism. In A. Bruns, E. Skogerb $\varnothing$, C. Christensen, A. O. Larsson, \& G. Enli (Eds.), The Routledge companion to social media and politics (pp. 89-103). Abingdon: Routledge.

Broersma, M., \& Koopmans, J. (2010). Identiteitspolitiek: Media en de constructie van gemeenschapsgevoel [Identity Politics: Media and the construction of sense of community]. Hilversum: Verloren.

Bruns, A., \& Burgess, J. (2011). The use of Twitter hashtags in the formation of ad hoc publics. Paper presented at The 6th European consortium for political research (ECPR) general conference 2011, Reykjavik, Iceland.

Chadwick, A. (2017). The hybrid media system: Politics and power. Oxford: Oxford University Press.

Colleoni, E., Rozza. A., \& Arvidsson, A. (2014). Echo chamber or public sphere? Predicting political orientation and measuring political homophily in Twitter using big data. Journal of Communication, 64(2), 317-332.

Conboy, M. (2006). Tabloid Britain. Abingdon: Routledge.

Conboy, M., \& Eldridge, S. (2018). Journalism and public discourse. In C. Cotter, \& D. Perrin (Eds.), The Routledge handbook of language and media (pp. 164-177). Abingdon: Routledge.

Couldry, N., Livingstone, S., \& Markham, T. (2007). Connection or disconnection? Tracking the mediated public sphere in everyday life. In R. Butsch (Ed.), Media and public spheres (pp. 28-42). Basingstoke: Palgrave.
Curran, J., \& Seaton, J. (2009). Power without responsibility. Abingdon: Routledge.

Dahlgren, P. (2005). The internet, public spheres, and political communication: Dispersion and deliberation. Political Communication, 22(2), 147-162.

Eldridge, S., \& Bødker, H. (2018). Negotiating uncertain claims: Journalism as an inferential community. Journalism Studies, 19(13), 1912-1922.

Eldridge, S., \& Steel, J. (2016). Normative expectations. Journalism Studies, 17(7), 817-826.

Esteve Del Valle, M., \& Borge Bravo, R. (2018). Echo chambers in parliamentary Twitter networks: The Catalan case. International Journal of Communication, 12, 1715-1735.

Fraser, N. (1990). Rethinking the public sphere: A contribution to the critique of actually existing democracy. Social Text, 25/26, 56-80.

Freeman, L. C. (1979). Centrality in social networks. Conceptual clarification. Social Networks, 1(3), 215-239.

Graham, T., Jackson, D., \& Wright, S. (2015). "We need to get together and make ourselves heard": Everyday online spaces as incubators of political action. Information, Communication \& Society, 19(10), 1373-1389.

Graham, T., Broersma, M., Hazelhoff, K., \& van't Haar, G. (2013). Between broadcasting political messages and interacting with voters: The use of Twitter during the 2010 UK general election campaign. Information, Communication \& Society, 16(5), 692-716.

Graham, T., Jackson, D., \& Broersma, M. (2018). The personal in the political on Twitter: Towards a typology of politicians' personalized Tweeting behaviours. In J. Schwanholz, T. Graham, \& P. Stoll (Eds.), Managing democracy in the digital age (pp. 137-157). Cham: Springer.

Griffin, C. (1996). The essentialist roots of the public sphere: A feminist critique. Western Journal of Communication, 60(1), 21-39.

Gurevitch, M., Coleman, S., \& Blumler, J. (2009). Political communication-Old and new media relationships. The ANNALS of the American Academy of Political and Social Science, 625(1), 164-180.

Habermas, J. (1981). The theory of communicative action. Boston, MA: Beacon Press.

Habermas, J. (1989). The structural transformation of the public sphere. Cambridge, MA: MIT Press.

Hallin, D., \& Mancini, P. (2004). Comparative media systems. Cambridge: Cambridge University Press.

Hampton, M. (2010). The fourth estate ideal in journalism history. In S. Allan (Ed.), The Routledge companion to news and journalism (pp. 3-12). Abingdon: Routledge.

Harder, R., \& Paulussen, S. (2016). Making sense of the Twitter buzz. Digital Journalism, 4(7), 933-943.

Hasebrink, U. (2017). Audiences and information repertoires. In B. Franklin \& S. A. Eldridge II (Eds), The Routledge companion to digital journalism studies (pp. 364-374). Abingdon: Routledge. 
Hepp, A. (2013). The communicative figurations of mediatized worlds: Mediatization research in the times of the "mediation of everything". European Journal of Communication, 28(6), 615-629.

Hepp, A., Hjarvard, S., \& Lundby, K. (2015). Mediatization: Theorizing the interplay between media, culture and society. Media, Culture \& Society, 37(2), 314-324.

Kane, G., Alavi, M., Labianca, G., \& Borgatti, S. (2014). What's different about social media networks? MIS Quarterly, 38(1), 275-304.

Katz, E. (1988). Disintermediation: Cutting out the middle man. Intermedia, 16(2), 30-31.

Katz, E., \& Dayan, D. (1994). Media events. Cambridge, MA: Harvard University Press.

Lasorsa, D. L., Lewis, S. C. \& Holton, A. E. (2012). Normalizing Twitter. Journalism Studies, 13(1), 19-36.

Marres, N. (2005). Issues spark a public into being: A key but often forgotten point of the Lippmann-Dewey debate. In B. Latour \& P. Weibel (Eds.), Making things public (pp. 208-217). Cambridge, MA: MIT Press.

Marwick, A., \& boyd, d. (2010). I tweet honestly, I tweet passionately: Twitter users, context collapse, and the imagined audience. New Media \& Society, 13(1), 114-133.

Marx Ferree, M., Gamson, W. A., Gerhards, J., \& Rucht, D. (2002). Four models of the public sphere in modern democracies. Theory and Society, 31(3), 289-324.

Nerone, J. (2015). The media and public life: A history. Cambridge: Polity.

Padovani, C., \& Pavan, E. (2016). Global governance and ITCs: Exploring online governance networks around gender and media. Global Networks, 16(3), 350-371.

Papacharissi, Z. (2004). Democracy online: Civility, politeness, and the democratic potential of online political discussion groups. New Media Society, 6(2), 259-283.

Papacharissi, Z. (2014). On networked publics and private spheres in social media. In J. Hunsinger \& T. Senft (Eds.), The social media handbook (pp. 144-158). Abingdon: Routledge.

Parmelee, J. H. (2013). Political journalists and Twitter: Influences on norms and practices. Journal of Media Practice, 14(4), 291-305.

Pérez-Altable, L. (2015). Social media and the 2014 European Parliament election: The case of Podemos. Pa- per presented at Political agency in the digital age. Media, participation and democracy, Copenhagen, Denmark.

Poor, N. (2005). Mechanisms of an online public sphere: The website slashdot. Journal of ComputerMediated Communication, 10(2). https://doi.org/ 10.1111/j.1083-6101.2005.tb00241.x

Richards, B. (2018). News media and the emotional public sphere. International Journal of Communication, 12, 2040-2051.

Ross, K., Fountaine, S., \& Comrie, M. (2015). Facing up to Facebook: Politicians, publics and the social media(ted) turn in New Zealand. Media, Culture \& Society, 37(2), 251-269.

Siebert, F. S., Peterson, T., \& Schramm, W. (1956). Four theories of the press. Urbana, IL: University of Illinois Press.

Steel, J. (2017). Reappraising journalism's normative foundations. In C. Peters \& M. Broersma (Eds.), Rethinking journalism revisited (pp. 35-48). Abingdon: Routledge.

Steel, J., \& Broersma, M. (2016). Redefining journalism in the era of the mass press, 1880-1920. Abingdon: Routledge.

Strömbäck, J. (2008). Four phases of mediatization: An analysis of the mediatization of politics. Press/Politics, 13(3), 228-246.

Strömbäck. J., \& Esser, F. (2017). Political public relations and mediatization. In P. Van Aelst \& S. Walgrave (Eds.), How political actors use the media (pp. 63-83). Basingstoke: Palgrave Macmillan.

Tromble, R. (2018). Thanks for (actually) responding! How citizen demand shapes politicians' interactive practices on Twitter. New Media \& Society, 20(2), 676-697.

Van Aelst, P., \& Walgrave, S. (2017). Information and arena. In P. Van Aelst \& S. Walgrave (Eds.), How political actors use the media (pp. 1-17). Basingstoke: Palgrave Macmillan.

Waisbord, S. (2013). Reinventing professionalism. Cambridge: Polity.

Warner, M. (2002). Publics and counterpublics. Public Culture, 14(1), 49-90.

Wijfjes, H. (2017). Digital humanities and media history: A challenge for historical newspaper research. Journal for Media History, 20(1), 4-24.

\section{About the Authors}

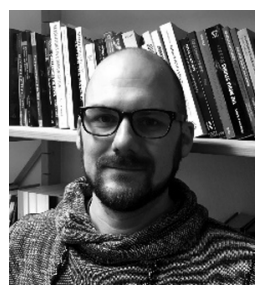

Scott A. Eldridge II is an Assistant Professor with the Centre for Media and Journalism Studies at the University of Groningen. He researches digital journalism and journalistic boundaries. He is the author of Online Journalism from the Periphery: Interloper Media and the Journalistic Field (2018) and co-editor with Bob Franklin of the Routledge Companion to Digital Journalism Studies (2017) and Routledge Handbook of Developments in Digital Journalism Studies (2019). He is an Associate Editor and Reviews Editor for the journal Digital Journalism. 


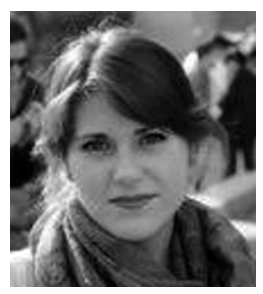

Lucía García-Carretero is a Predoctoral Researcher in the Communication Department at Universitat Pompeu Fabra (Barcelona). She has a Bachelor's degree in Journalism (Universidad de Valladolid) and a Master's degree in Social Communication (Universitat Pompeu Fabra). Her main lines of research are online political communication from new political organizations and digital journalism. Her recent publication is "From social movements to political parties. Barcelona en Comú's electoral message, uses and limitations on Twitter during 2015 city council election" (2018).

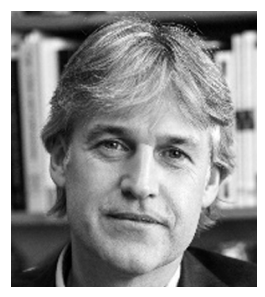

Marcel Broersma is Professor and Director of the Centre for Media and Journalism Studies at the University of Groningen. His research focuses on the current and historical transformation of journalism, and how journalists, politicians and citizens use social media in particular. He has published numerous articles in peer-reviewed journals, chapters, monographs, edited volumes and special journal issues on social media, transformations in journalism, journalism history and political communication. Among his recent publications are: Rethinking Journalism Again. Societal Role and Relevance in a Digital Age (2017; co-edited with Chris Peters) and Redefining journalism in the era of the mass press, 1880-1920 (2016; co-edited with John Steel). He chairs the boards of the Dutch Research School for Media Studies (RMeS) and of eHumanities.nl. 